\title{
An Overview to Chip-based Power Transistor and Prognostics Techniques
}

\author{
M. H. Abdul Halim, N. Buniyamin, N. Naoe, A. Imazawa and M. S. Rosman
}

\begin{abstract}
Power ratings and switching capability have been the main performance characteristics in the development of power transistors. To safely secure the performance reliability of its operation, a prognostics study for power transistor was introduced. The prognostics of power transistors enable the assessment of its health condition and prediction of remaining useful lifetime (RUL), given the current characteristics and loading condition. This paper presents the classification of smallsignal transistor and power transistor, and the applications of power transistors. Three types of prognostics method: Model-driven, Data-driven and Hybrid method are summarized and compared. Subsequently, a new prognostics methodology for RUL prediction of power MOSFET due to active and passive thermal stress is proposed. The proposed method is based on the data-driven methodology that will utilize the characteristics of voids, and $\mathrm{ON}-\mathrm{State}$ resistance, $\boldsymbol{R}_{d s, o n}$ as input for the proposed algorithm. The algorithm will be termed as RULPOV (Remaining Useful Life Prediction based on Voids). The proposed method is expected to improve the RUL prediction as well as to minimize the reliance on junction temperature measurement.
\end{abstract}

Index Terms-Small-signal MOSFET, Power MOSFET, Prognostics, model-driven, data-driven, failure mechanism, failure precursor.

\section{INTRODUCTION}

$\mathrm{H}$ EALTH MONITORING and failure prediction of power modules have become extremely important in the semiconductor field. Especially, when the electronics and electrical system are now dictated by and rely on the power modules.

This manuscript is submitted on 9th October 2019 and accepted on 10th May 2020. M. H. Abdul Halim is with the Department of Science and Technology, International College of Technology Kanazawa, Ishikawa 921-8601 Japan (email:mhazwan@neptune.kanazawa-it.ac.jp)

N. Naoe and A. Imazawa is with the Department of Electrical and Electronic Engineering, International College of Technology Kanazawa, Ishikawa 9218601 Japan (e-mail: naoe@neptune.kanazawa-it.ac.jp)

A. Imazawa is with the Department of Global Information and Management, International College of Technology Kanazawa, Ishikawa 921-8601, Japan (email: imazawa@neptune.kanazawa-it.ac.jp).

N. Buniyamin and M. S. Rosman are with the Faculty of Electrical Engineering, Universiti Teknologi MARA, 40450 Shah Alam, Selangor, Malaysia (e-mail: nbuniyamin@uitm.edu.my,msyafiqr@gmail.com).

1985-5389/C 2021 The Authors. Published by UiTM Press. This is an open access article under the CC BY-NC-ND license (http://creativecommons.org/ licenses/by-nc-nd/4.0/).
The effort of monitoring and predicting failure is commonly known as prognostics. It is an engineering discipline that focuses on predicting the health condition and remaining useful lifetime (RUL) based on its current condition and degradation characteristics. Its main objective is to prevent sudden failure from occurring which can result in a catastrophic event, especially for mission-critical applications. Besides, prognostics also help the application industry to better understand the scope and limitation of power modules. This knowledge will directly improve the current tedious, timeconsuming and costly maintenance routines. Thus, maintenance can be scheduled effectively without exhausting resources due to overestimation or underestimation of modules health conditions.

The prognostics effort of power modules started in the early 1990s through several government-funded research programs. This effort was initiated since power transistors are the most unreliable device that causes failure of the inverters after capacitor, as reported by MILitary STanDard (MIL-STD 217). A research program called LESIT (LeistungsElektronik Systemtchnik und InformationTechnologies) was the earliest research introduced in 1994 by the Swiss government. Its objective was to determine the lifetime of standard power modules. The samples used in the program are collected from different suppliers coming from Europe and Japan. Another program called RAPSDRA (Reliability of Advanced high Power Semiconductor Device for Railway Traction Application) was started in 1996 to model the failure rate of Insulated-Gate Bipolar Transistor (IGBT) multichip modules as a current converter in a realistic railways traction environment.

The application of prognostics techniques in various fields for reliability assessments can be observed from several publications. The scope of discussion includes the framework, method of prognostics, advantages, disadvantages, and potential areas for developing reliable prognostics techniques. A. Heng [1] and M. S. Kan [2] review the application of prognostics techniques for predicting rotating machinery failure. J. Z. Sikorska [3] discuss the important steps and characteristics in selecting the appropriate prognostics model for the prediction of the remaining useful life of engineering assets. The model selection was made with the consideration of the specific business environment. B. Sun [4] review the latest information regarding the prognostics of high-power white LEDs. The authors have successfully reviewed in detail the 
present prognostics techniques and highlighted their efficiency and accuracy.

This paper is organized as follows. Section II introduces the characteristics that classify between power transistor and smallsignal transistor followed by the application of the power transistor. Section III presents the type of failures, failure mechanism and failure precursor associates with power transistors due to thermal stress. Section IV summarizes the three types of prognostics methods including their concept, advantages, and disadvantages. Section V presents a proposed prognostics methodology to predict the RUL of power MOSFETs due to simultaneous thermal stress on the solder layer.

\section{Characteristics OF POWER TRANSISTOR AND ITS APPLICATIONS}

Transistors are regarded as the most important invention of the $20^{\text {th }}$ century. It has been the fundamental component that can be found in digital and analog switches, power regulators and signal amplifiers. It is well-known that electronic component such as transistor enables better control of energy management compared to mechanical-based components. This advantage of transistors becomes the main motivation of its continuous improvement starting from the year 1947 where it is being introduced until now. The reasons for transistor evolutions are (some):

- its "amplifying" ability for wider applications

- reduced footprint for portability of equipment

- better efficient energy consumption

- achieving greater breakdown voltage for high power application

- achieving a better frequency response for high-speed switching application

The key event in the evolution of transistors from the introduction of vacuum triode to commercially introduced power MOSFET is presented in Figure 1.

In general, transistors can be categorized in two categories: power transistor and/or small-signal transistor. However, there is no absolute dividing line to differentiate between these two categories without visualizing their internal construction. These transistors also share the same working principle. However, if the categorization is to be performed, it can be done by categorizing them in term of:

- power rating, and

- packaging

The word 'power' indicates the application of transistors in high power electrical system. For this purpose, power transistors are said to be designed to have higher power ratings compared to the small-signal transistor. Most design engineers agreed that any transistor that can handle more than $1 \mathrm{~A}$ of current can be considered as a power transistor and transistors that handle less than $1 \mathrm{~A}$ of current can be considered as a smallsignal transistor. Higher power rated transistor is produced to meet the demand for high power applications. N. Mohan et. al. [5] have summarized the switching speed and voltage rating of power transistors as shown in Figure 2.

As power transistors handle bigger power, they are usually in packages that work with heat sinks. The heat sink is used to dissipate heat generated during the operation. This feature can be used to differentiate between power transistors and smallsignal transistors. There are several types of packaging style is being used for power transistors. Some examples of the packaging style include TO-220, TO-220F, TO-247 (or T0-3P), TO-257, etc. The difference in packaging for small-signal transistors and power transistor is shown in Figure 3.



Fig. 1 Important events of transistor evolution from vacuum tube triode to power MOSFET

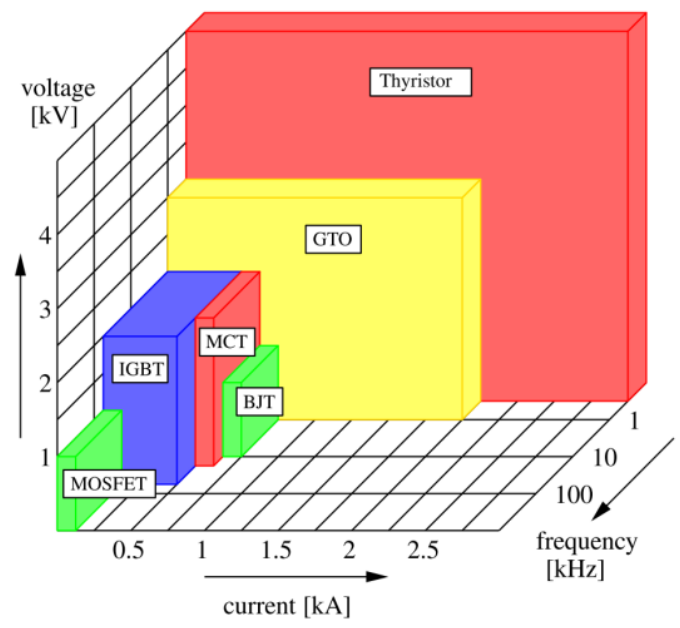

Fig. 2 Summary of power transistor device capabilities [5] 


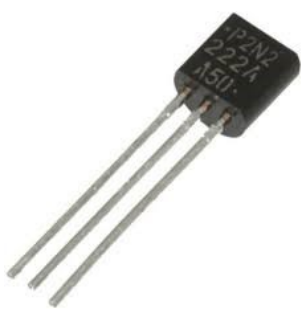

A
B

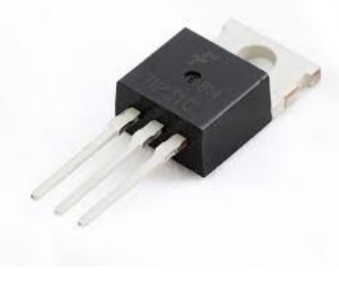

Fig. 3 A) Small-signal transistor, and B) Power transistor with TO-220 packaging style

In electronic and electrical systems, transistors are responsible to provide reliable and efficient power and energy management to the system. They are known as the 'heart' of the system. The word power and energy management describe and indicate the application of transistors as switching devices, power converters and amplifiers in the system. Its application which ranged from low to high power is depicted in a graph by [6] as shown in Figure 4. The graph shows the application of power MOSFET (Metal Oxide Semiconductor Field Effect Transistor) in various applications based on power rating.

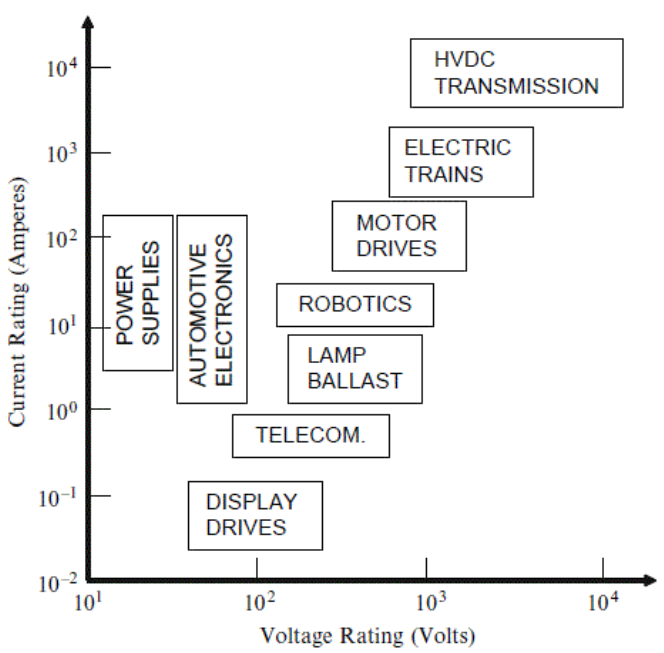

Fig. 4 Various current and voltage rating of MOSFETs [6]

Power transistors are being used in four general market segments: automotive, home appliance, energy and electrical system, and industrial instrumentation. The current trend of application and development of power transistors is focused on accommodating the demand for higher complex engineering applications in the automotive field. The main objective of its application in the field are 1) to improve the performance and functionality of automobile and 2) to minimize global warming. These two objectives are achieved by making the car body lighter, better fuel efficiency as well as reducing the cost of the automotive system. The system that utilizes the power transistor is electronic ballast circuit, electronics control circuits (ECUs), motor control of power windows, oil pressure control and DCAC converter. Their application involves a power transistor with the range of breakdown voltage from $60 \mathrm{~V}$ to $600 \mathrm{~V}$ although they can sustain up to $5 \mathrm{~K} \mathrm{~V}$.

\section{Stress, FAILURE MECHANISM AND FAILURE PRECURSOR}

As technology advancement is rapidly ongoing, demand for a more complex engineering system/subsystem/component which requires better electrical power management has increased. For example, denser and more complicated design of power transistors is required and this increases the device vulnerability towards thermal and electrical stress. These stresses affect the device performance as well as increasing the chance of catastrophic failure of a system. The study of the type of stress, the failure mechanism and the failure precursor of power MOSFET is very important. This section intends to summarize and analyze failure characteristics of power transistors so that it will provide necessary information to design, manufacture and maintenance personnel to better improve the device reliability in terms of chip design or the packaging design.

Power transistor work as a switch will experience rapid turning $\mathrm{ON}$ and OFF. This change of state contributes to rapid thermal transient which causes thermal stress [7]. S. P. Patil [8] defines thermal stress as the thermal expansion due to the increase in temperature of the device. This thermal transient is induced either by local thermal generated (self-heating) and/or by ambient thermal due to surrounding electrical components.

Power transistors are constructed and packaged by several layers of different materials. These materials exhibit different thermal expansion coefficients (CTE). CTE is a measurement quantity used to indicate the fractional change in size per degree change of temperature considering constant pressure. In other words, it is a measure of the ability of materials to expand due to the increase in temperature. As the materials glued together, the material with lower CTE will tend to crack when the expansion exceeds its elastic capability. For example, the solder joint between die attach-ceramic substrate has the highest CTE difference. Due to CTE differences and high temperature, fatigue crack and voids could occur.

Figure 5 illustrates the typical flow of heat dissipation of the power MOSFET package in agreement with the study conducted by M. S. Rosman [9]. The study state that the heat is dissipated through conduction from the molded compound to die, solder layer, heatsink, Printed Circuit Board (PCB) before it is released to ambient. Solder layer is known as the most affected layer due to thermal stress [10]. The part of the solder layer that has cracks or voids in it will have higher thermal impedance. Due to this, heat will be forced to travel laterally toward the lower thermal impedance area [10]. Thermal impedance is a quantity used to quantify the resistance on heat dissipation, which significantly increased with the existence of void [7], [8], [10]. Voids impede the uniformity of heat distribution in the silicon chip which contributes to the formation of hotspots on the surface of the chip [11]. For reliability concern, the highest void size allowed by industries is not more than $10 \%$ of the total solder joint area [12]. Figure 6 shows the two types of void, Coalesced and Scattered that can be found inside the solder layer of a MOSFET. C-mode in 
Scanning Acoustic Microscopy (C-SAM) method is used to obtain the void images. Figure 7 then illustrates the effect on heat dissipation due to the existence of voids caused by solder layer fatigue.

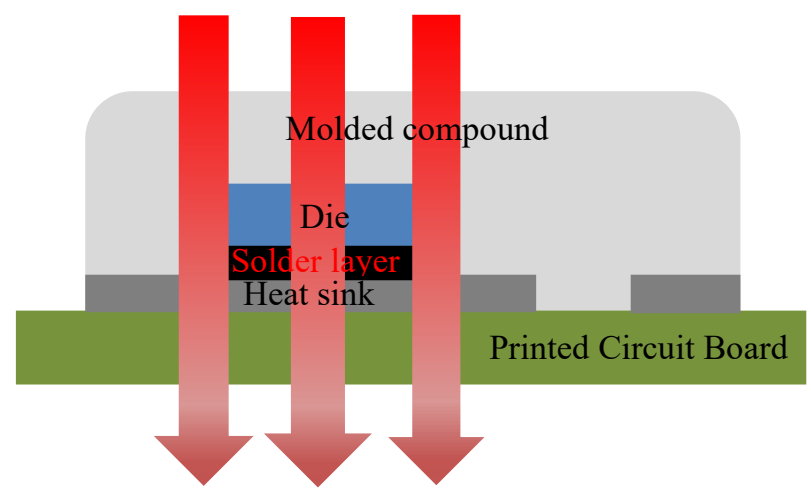

Fig. 5 Heat flow of power MOSFET
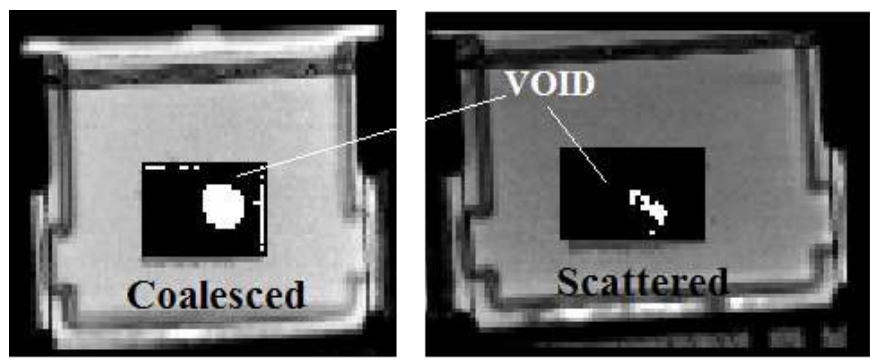

Fig. 6 Two types of void inside the solder layer of a MOSFET [9]



Fig. 7 Heat dissipation due to the existence of voids in the solder layer

$$
\begin{gathered}
\text { Voids } \propto R_{\text {thermal }} \\
P_{\text {Heat }}=I^{2} R_{\text {thermal }} \\
\text { Voids } \propto P_{\text {Heat }}
\end{gathered}
$$

Equation 1 shows that the thermal impedance, $R_{\text {thermal }}$ increases with the increase of voids in the solder layer. The increase of thermal impedance results in the increase of hotspots $P_{\text {Heat }}$. From these relationships, it can be concluded that voids are positively related to the junction temperature of the transistor. Studies on the effect of voids has been done thoroughly either by simulation and experimental methodology. Authors [1], [3], [10], [13]-[15] perform simulation using Finite Element Analysis (FEA) to investigate the effect of voids characterized by size and location on thermal effect toward power modules. S. P. Patil [8] found that a $20 \%$ void in the solder layer could increase the thermal impedance by $1{ }^{\circ} \mathrm{C} / W$ to $8{ }^{\circ} \mathrm{C} / \mathrm{W}$ for a particular device and void configuration. While J. Chang [12] found that circular-shaped voids with $20 \%$ of the total solder layer area voids would cause the chip temperature to rise more than $5.1^{\circ} \mathrm{C}$ depending on the void size and locations. The other authors agree that voids in the solder layer increase the thermal resistance of the device and resulting in an increase of junction temperature.

Thermal stress relative to time induces degradation, which can result in either random or wear-out failures. The degradation of the solder layer, aluminum reconstruction, and bond wire lift-off are known as common failure mechanisms induced by the thermal stress. As for power transistors, degradation of the solder layer is known as the main failure cause for the wear-out failures [16]. There were several studies dedicated to determining the characteristics of power transistor affected by constant thermal transient due to either power cycles or thermal cycles. This characteristic, known as failure precursor is used to determine the types of failure mechanisms (degradation) as well as the degree of the degradation. Figure 8 shows the types of failure precursors for thermal stress used in power transistor prognostics based on the literature review of the research paper ranged from 2008 to 2017.

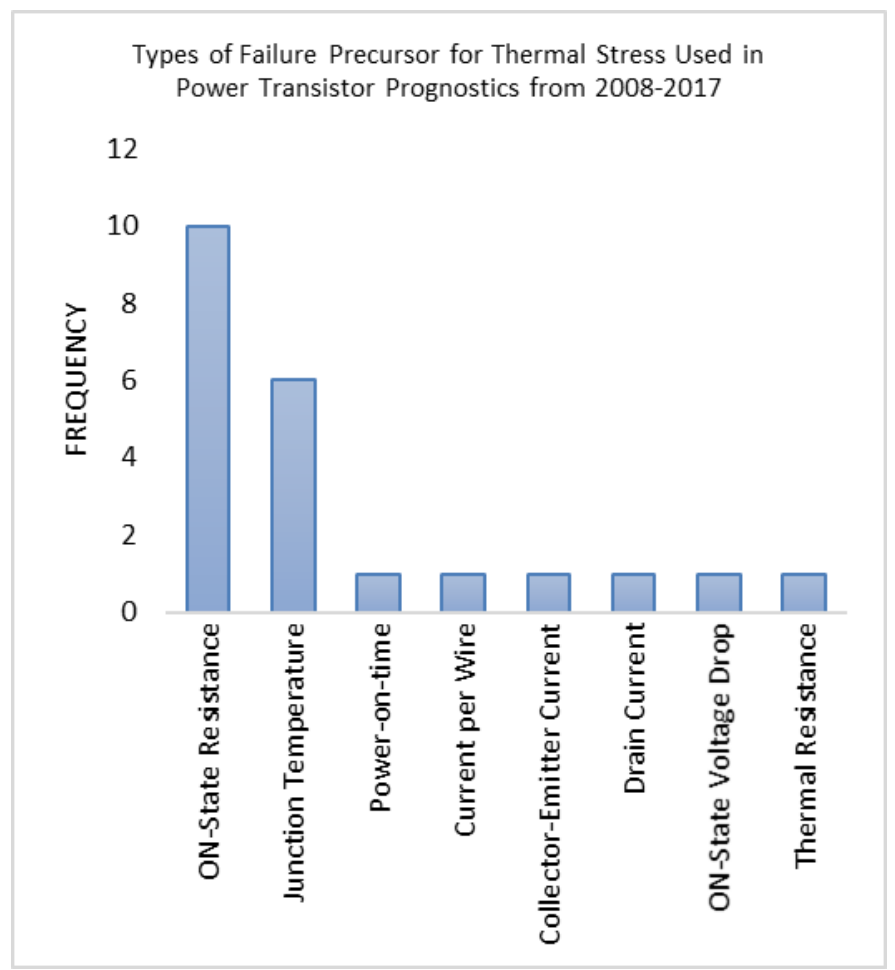

Fig. 8 Types of failure precursor for thermal stress used in power transistor prognostics from $2008-2017$.

As previously mentioned, the degradation of the solder layer contributes to the increase of junction temperature due to inefficient heat flow. For this reason, the junction temperature is the most direct parameter used as a failure precursor for thermal-based degradation. However, the junction temperature is difficult to measure because it is buried in the package itself [17]. To overcome the problem, an equivalent electrothermal model was built to calculate the junction temperature. ON-State resistance, $R_{d s, o n}$ is one of the most popular parameters of the 
electrothermal model for measurement of junction temperature because of its practicality and easier to measured [18], [19]. S.Duzmez [19] state the equation of $R_{d s, o n}$ that is related to the junction temperature.

$R_{d s, \text { on }}=R_{\text {source }}+R_{C h}+R_{j}+R_{A}+R_{D}+R_{\text {Sub }}+R_{\text {wcml }}$

\section{PRognostics Methods AND its APPLICATION FOR POWER TRANSISTOR}

Accurate prognostics technique enables assessments of device health condition and prediction of RUL (Remaining Useful Life) that benefits the electronic manufacturer, endproduct manufacturer and consumer. This information gives a better perspective on how the device or systems behave under particular loading and environmental condition. A reliable prognostic allows the change of system maintenance strategy which is previously based on "fail-and-fix" to a more adaptive strategy called "predict-and-prevent". Sudden catastrophic failure of safety-critical and mission-critical applications which could cause the loss of human lives can be prevented. Some examples of the safety-critical and mission-critical applications include automobile, offshore wind turbine, traction control and aeronautics. Generally, prognostics methods are classified into three types of methods: Model-Driven, Data-Driven and Hybrid. In this section, the review of these three methods is presented followed by their application for the power transistor. This review is based on the literature review of selected research papers in the context of power transistors from 2008 to 2017. Table 1 tabulates the summary of the selected research papers.

\section{A. Model-Driven Method}

The model-driven method which also known as the physicsof-failure method (PoF) relies on a deep understanding of how the physical system works and its behavior under constant pressure. From the understanding, a mathematical model representing the system/subsystem/component degradation and failure mechanism under continuous load (power or thermal cycle) is developed. M. Pecht [20] describes the flows of the model-driven method as shown in Figure 9.

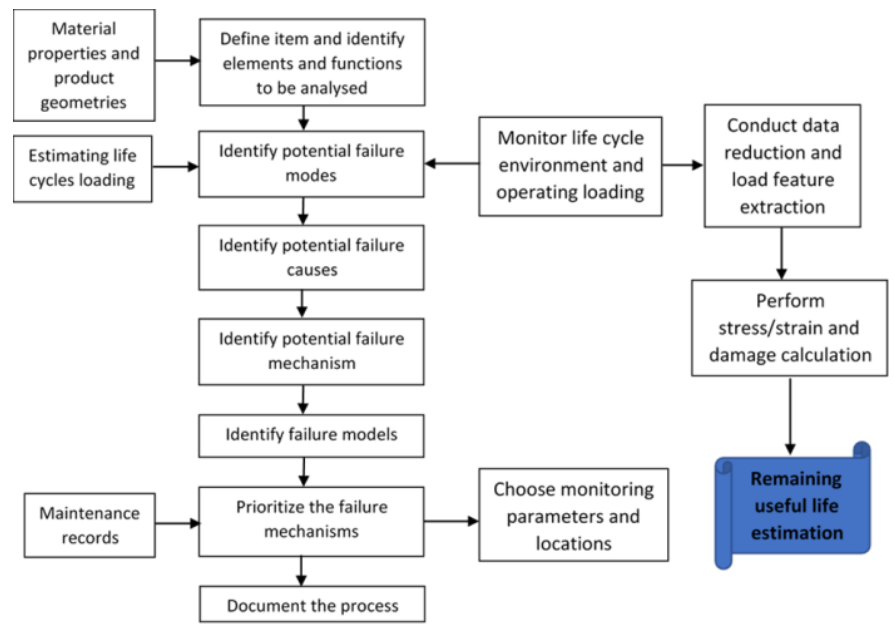

Fig. 9 Flows of model-driven method [20]
TABLE 1

RESEARCH PERFormed IN THE AREA OF POWER TRANSISTOR Prognosis, CATEGORIZED BASED ON METHODS, AND TYPES OF APPLIED STRESS FROM

\begin{tabular}{|c|c|c|c|}
\hline \multicolumn{4}{|c|}{$2008-2018$} \\
\hline Method Type & Authors & Model / Method & Types of Stress \\
\hline Model-Driven & $\begin{array}{l}1 .[7] \\
\text { 2. [21] } \\
\text { 3. }[22] \\
\text { 4. [23] } \\
\text { 5. [24] } \\
\text { 6. }[25] \\
\text { 7. [26] } \\
\text { 8. [27] } \\
\text { 9. }[28] \\
\text { 10. [17] } \\
\text { 11. [29] } \\
\text { 12. [30] } \\
\text { 13. [31] } \\
\text { 14. }[32] \\
\text { 15. [33] }\end{array}$ & $\begin{array}{l}\text { Coffin Mason } \\
\text { Bayerer's } \\
\text { Linear Damage } \\
\text { Particle Filter } \\
\text { Exponential } \\
\text { Weibull Statistics } \\
\text { Arrhenius } \\
\text { Coffin Mason } \\
\text { Reaction-Diffusion } \\
\text { and Transistor } \\
\text { Theory } \\
\text { Miner's Rule } \\
\text { Statistical } \\
\text { Norris-Landzberg } \\
\text { Coffin-Mason } \\
\text { Logarithmic } \\
\text { Extrapolation } \\
\text { Coffin-Mason }\end{array}$ & $\begin{array}{l}\text { Thermal and } \\
\text { Electrical } \\
\text { Thermal } \\
\text { Thermal } \\
\text { Thermal } \\
\text { Electrical } \\
\text { Thermal and } \\
\text { Electrical } \\
\text { Electrical } \\
\text { Thermal } \\
\text { Electrical } \\
\text { Thermal } \\
\text { Thermal } \\
\text { Thermal } \\
\text { Thermal } \\
\text { Thermal } \\
\text { Thermal }\end{array}$ \\
\hline Data-Driven & $\begin{array}{l}16 .[34] \\
\text { 17. }[35] \\
\text { 18. }[36] \\
\text { 19. }[37] \\
20 .[38] \\
21 .[39] \\
22 .[40] \\
23 .[41] \\
24 .[42] \\
25 .[43] \\
26 .[44] \\
27 .[18] \\
\text { 28. }[45]\end{array}$ & $\begin{array}{l}\text { Gaussian Process } \\
\text { Regression } \\
\text { Relevance Vector } \\
\text { Machine } \\
\text { Markov Chain } \\
\text { Kalman Filter } \\
\text { Kalman Filter } \\
\text { Particle Filter } \\
\text { Exponential } \\
\text { Empirical } \\
\text { Exponential } \\
\text { Empirical } \\
\text { Exponential } \\
\text { Empirical } \\
\text { Exponential } \\
\text { Empirical } \\
\text { Linear Function } \\
\text { with Bayesian } \\
\text { Inference Estimator } \\
\text { Least Square } \\
\text { Maximum } \\
\text { Likelihood and } \\
\text { Bayesian } \\
\text { Estimation }\end{array}$ & $\begin{array}{l}\text { Thermal } \\
\text { Thermal } \\
\text { Electrical } \\
\text { Thermal } \\
\text { Electrical } \\
\text { Thermal } \\
\text { Thermal } \\
\text { Thermal } \\
\text { Electrical } \\
\text { Thermal } \\
\text { Thermal } \\
\text { Electrical } \\
\text { Not stated }\end{array}$ \\
\hline Hybrid & $\begin{array}{l}\text { 29. [46] } \\
\text { 30. [47] }\end{array}$ & $\begin{array}{l}\text { Regression and } \\
\text { Particle Filter } \\
\text { Gaussian Process } \\
\text { Regression and } \\
\text { Extended Kalman } \\
\text { Filter }\end{array}$ & $\begin{array}{l}\text { Electrical } \\
\text { Thermal }\end{array}$ \\
\hline
\end{tabular}

K. Medjaher [48] presents a summary of the advantages and drawback of the model-driven method (salient points are tabulated below in Table 2):

TABLE 2

ADVANTAGES AND DRAWBACKS OF MODEL-DRIVEN METHOD AS SUMMARIZED BY K. MEDJAHER [48]

\begin{tabular}{|l|l|}
\hline \multicolumn{1}{|c|}{ Advantages } & \multicolumn{1}{c|}{ Drawbacks } \\
\hline High Precision & Need of degradation model \\
\hline Determinic approach & High cost of implementation \\
\hline $\begin{array}{l}\text { System-oriented approach: propogation } \\
\text { of the failure in the whole system }\end{array}$ & $\begin{array}{l}\text { Difficult to apply on complex } \\
\text { systems }\end{array}$ \\
\hline
\end{tabular}


These advantages and disadvantages are mainly contributed by the application of the physical model in the methodology. The accuracy and precision of prediction depend on the fidelity of the developed physical model [49]. However, constructing a high fidelity model is time consuming, costly and required an intensive computation process. These disadvantages become more significant for a more complex system [48].

There are two issues in the application of model-driven based prognostics methods for RUL prediction of power transistor: (1) dependency of the applied model to the information regarding junction temperature, and (2) normalization of other concurrent failure mechanisms in considerations. The accuracy of the model-driven based prognostics method is highly dependent on the measurement of junction temperature [29]. As described in the earlier section, several parameters are being studied to determine the best failure precursor. Some failure precursor reacts differently for different failure mechanism. This uncertainty affects the accuracy of junction temperature measurement, which contributes to the prediction error. As the variation of junction temperature mainly caused by the degradation of the solder layer with the consideration of constant loading, reliance on junction temperature measurement can be minimized by directly using the characteristics of voids that exist in the solder layer as the failure precursor.

Application of any particular model required normalization of other parameters or precursors of other failure mechanisms that may occur at the same time [29]. For example, drain current, $I_{D}$ is known as failure precursor for dioxide degradation and solder fatigue [7]. Ignoring one failure mechanism might give an inaccurate analysis of the cause of failure. This normalization of parameters ignoring the complexity of the actual operation condition and contribute to prediction error [4], [35].

\section{B. Data-Driven Method}

The data-driven method compared to the model-driven method does not require any physical model that relates to the failure mechanism and module parameters. This might be the major advantage compared to a model-driven method for prognosis of complex engineering system/component where the physical model is unavailable or when the information of failure mechanism is inadequate. Based on the experience data (data representing nominal and fault behavior of the system/components), an algorithm that connects the relationship between failure mechanism and failure precursor is obtained. M. Pecht [50] presented a methodology for the development of a data-driven algorithm as shown in Figure 10. The common data-driven approaches (as tabulated in Table 1) are Relevance Vector Machine (RVM), Kalman Filter, Particle Filter and Least Square [51][52]. Y. Zheng [35] applies the RVM method to predict the RUL of power MOSFETs dynamically. By using the information from the trained data, the degradation model is updated according to the predictive value and measured value. This corrective act makes sure that the generated model is based on the real-time operation.

This recursive nature of generating the RULs model is more reliable for complex actual operation conditions as no particular degradation model is used. However, data-driven is a data- hungry method that relies on a good bit of data to get a decent result. The accuracy of the predicted RUL is sensitive to the number of observed data [44]. It shows that enough data that cover the full range of expected variation and null cases are required to produce accurate RUL prediction. A more complex system will require more degradation data which involve a big number of samples, tedious measurement, and parameter acquisition process.

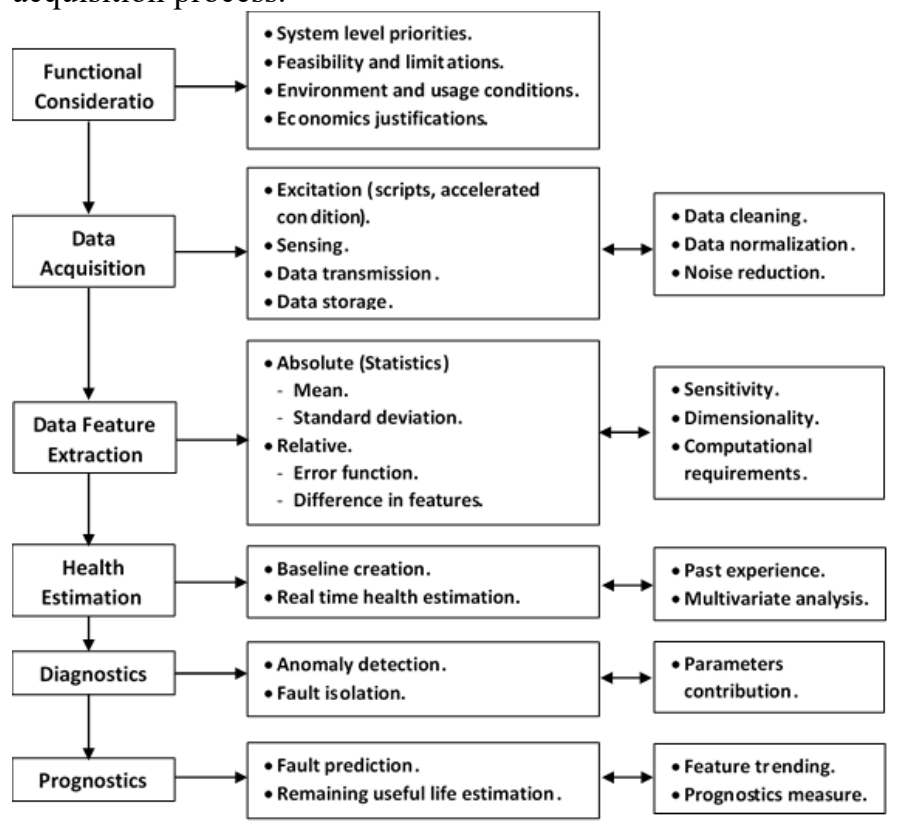

Fig. 10 Flows of data-driven method [50]

\section{Hybrid Method}

The hybrid method takes the advantages of both modeldriven and data-driven methods. Model-driven compensates the lack of data and data-driven compensates the lack of knowledge about the system physics [53]. The integration of model-driven and data-driven can be performed either two phases:

- Before RUL estimation which is called as pre-estimate where model-driven and data-driven are fused to perform RUL estimation

- After RUL estimation by fusing the result from each approach to obtain the final RUL called as post-estimate.

M. Pecht [54] presented a nine-step fusion approach for the RUL estimation of electronic products in his paper.

The main advantage of the hybrid method compared to the other two methods is its versatility and accuracy. A basic physical model of a system/component is sufficient to be used in this method because its lack in detail will be compensated by the data analysis in data-driven. Data-driven is great in discovering the hidden relationship which in turn gives more knowledge about the system behavior which will increase the accuracy of RUL estimation. However, to apply the method, there is still the need of constructing a basic physical model and methodology for data acquisition. This method will be very useful for the RULs estimation of a novel complex engineering 
system but might be resources consuming to be applied in component level.

\section{Proposed FAILURE PREDICTION}

This paper proposed a failure prediction methodology for RUL estimation of power MOSFET which degrades due to active and passive thermal stresses. It will be based on a datadriven method as the model represent the relationship between the two types of stress and the power MOSFET is unavailable. Since it is at the component level, it will resource consuming to use a hybrid method to estimate the RUL. Multiple regression prediction algorithms based on Supervised Learning Methods will be developed. The algorithm will be termed as RULPOV (Remaining Useful Life Prediction Algorithm based on Voids). The void characteristics (size and location) and ON-State resistance, $R_{d s, o n}$ will be the input for the RULPOV. Two advantages can be expected from this method, (1) void characteristics which regraded as basic quantities are used in prediction of RUL rather than junction temperature, the derived quantities. This action eliminates the dependency on the need for an accurate model to estimate the junction temperature. Reliance on junction temperature can be minimized and more accurate RUL can be predicted. (2) The second RULPOV input, the ON-State resistance, $R_{d s, o n}$ will function as 'AND' operator together with voids characteristics. This will make sure that the RUL will be only predicted when those two inputs are inagreements with each other. This will eliminate other variables (degradation) that may influence the RUL and make the characteristics of the void as the sole predictor. The framework of RULPOV is shown in Figure 11. The research methodology for experimental design and validation is as shown in Figure 12.

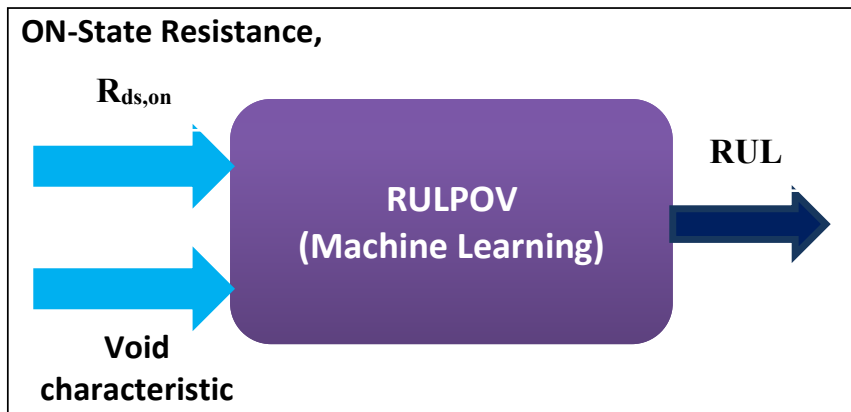

Fig. 11 Framework of RULPOV

\section{CONCLUSION}

The main purpose of this paper is to present the overview of prognostics techniques based on Model-driven, Data-driven, and Hybrid methods applied for prognostics of power transistors. A definition of the power transistor and its differences compare to the small-signal transistor is also presented. Even though the practice of prognostics on power modules has been studied for more than 20 years, the search for the reliable failure precursor for complex degradation phenomena of power modules are still ongoing. Prediction of RUL using a model-driven method, which relies heavily on junction temperature, must be reduced due to the complexity of measuring the junction temperature as discussed above. Further research will be conducted to improve the prognostics practice of power modules in terms of minimizing the reliance on junction temperature measurements. Also, the proposed datadriven methods will enable the practices of prognostics as of the actual operating condition without normalization of other failure mechanisms or precursors.

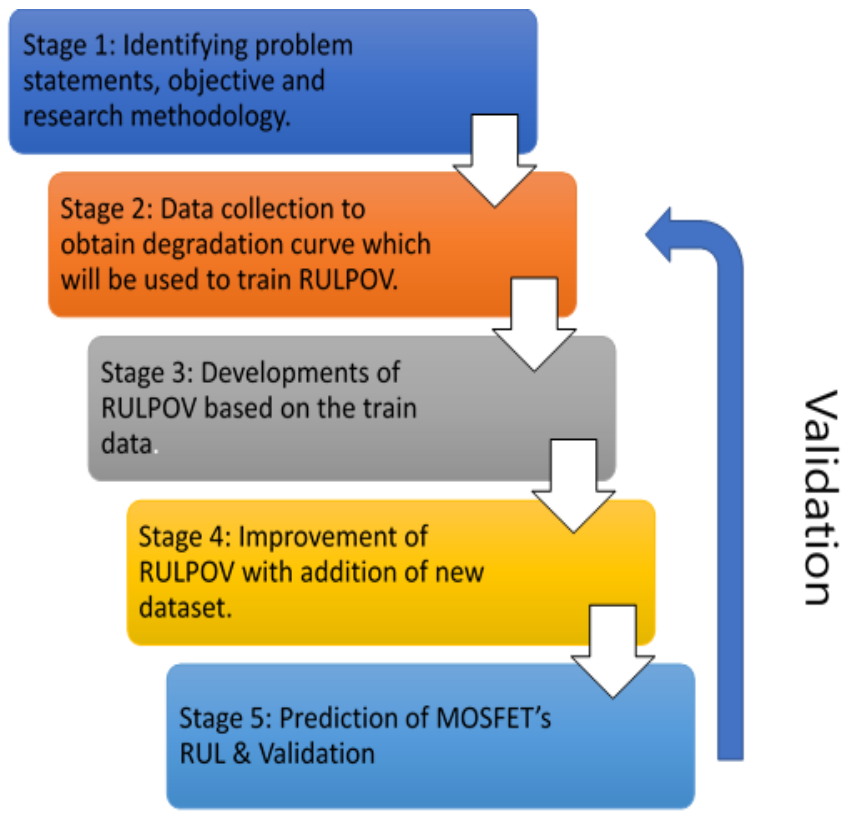

Fig. 12 Flow of Exprimental Design and Validation

\section{REFERENCES}

[1] A. Heng, S. Zhang, A. C. C. Tan, and J. Mathew. (2009, Apr). Rotating machinery prognostics: State of the art, challenges and opportunities. Mechanical System and Signal Procesing. 23(3), pp. 724-739.

[2] M. S. Kan, A. C. C. Tan, and J. Mathew. (2015, Oct). A review on prognostic techniques for non-stationary and non-linear rotating systems. Mechanical System and Signal Processing. 62-63, pp. 1-20.

[3] J. Z. Sikorska, M. Hodkiewicz, and L. Ma. (2011, Jul). Prognostic modelling options for remaining useful life estimation by industry. Mechanical System and Signal Processing. 25(5), pp. 1803-1836.

[4] B. Sun, X. Jiang, K. C. Yung, J. Fan, and M. G. Pecht. (2017, Aug). A Review of Prognostic Techniques for High-Power White LEDs. IEEE Transactions on Power Electronics. 32(8), pp. 6338-6362.

[5] N. Mohan, T. M. Undeland, and W. P. Robbins, "Power Electronics Converter, Application and Design." 2nd ed. JOHN WILEY\& SONS, INC, 2004, pp 1-821.

[6] B. J. Baliga, "Introduction," in Advances Power MOSFET Concepts. 1st ed. London: Springer US, 2010, pp. 2.

[7] A. Testa et al., "Stress analysis and lifetime estimation on power MOSFETs for automotive ABS systems," in IEEE annual PESC, Rhodes, Greece, 2008, pp. 1169-1175.

[8] S. Patil and G. Waghmare. (2015, Apr). Determination of Thermal Induced Stresses in Semiconductor Chip Package by using Finite Element Analysis: A Brief Review. International Journal of Engineering and Technical Research. 4(4), pp. 44-47.

[9] M. S. Rosman, N. Buniyamin, and M. H. A. Halim. (2017, Nov). The Effect of Void in Thermal Layer on MOSFET's Heat Dissipation. Advance Science Letters. 23(11), pp. 11170 - 11174.

[10] D. C. Katsis and J. D. VanWyk, "A finite element modeling of dynamic hot spot effects in MOSFET dies due to voiding in the solder die-attach," in IEEE 34th Annual PESC, Acapulco, Mexico, 2003, pp. 828-833.

[11] D. C. Katsis and J. D. van Wyk. (2006, Mar). A thermal, mechanical, and electrical study of voiding in the solder die-attach of power MOSFETs. IEEE Trans. on Comp. and Packaging Technologies. 29(1). pp. 127-136. 
[12] J. Chang, L. Wang, J. Dirk, and X. Xie. (2006, Mar). Finite element modeling predicts the effects of voids on thermal shock reliability and thermal resistance of power device. Weld. Journal. 85(3). pp. 63-s - 70-s.

[13] J. R. Celaya, N. Patil, S. Saha, P. Wysocki, and K. Goebel, "Towards Accelerated Aging Methodologies and Health Management of Power MOSFETs ( Technical Brief )," in 2009 PHM Society Conference, San Diego, California, 2009, pp. 1-8.

[14] M. Currie, S. Dowds, and N. Hackett. (2011, May). Achieving Thermal Control for Power Devices: Die Attach Solder Pastes for Varying Requirements. IEEE Transactions on Components, Packaging, and Manufacturing Technology. 1(4). pp. 457-478.

[15] M. Thomas (2007, April). Die-attach Materials and Processes: A Leadfree Solution for Power and High-power Applications. PennWell Corporation.

[16] X. Perpiñà, L. Navarro, X. Jordà, M. Vellvehi, J.-F. Serviere, and M. Mermet-Guyennet, "Reliability and Lifetime Prediction for IGBT Modules in Railway Traction Chains." in Reliability and Safety in Railway, 1st ed, INTECH, 2012, pp. 193-222.

[17] H. Huang and P. A. Mawby. (2013, Aug). A Lifetime Estimation Technique for Voltage Source Inverters. IEEE Transaction on Power Electronics. 28(8). pp. 4113-4119.

[18] S. Dusmez, S. H. Ali, M. Heydarzadeh, A. S. Kamath, H. Duran, and B. Akin. (2017, Jan). Aging Precursor Identification and Lifetime Estimation for Thermally Aged Discrete Package Silicon Power Switches. IEEE Trans. on Industry Applications. 53(1). pp. 251-260.

[19] S. Dusmez and B. Akin, "An accelerated thermal aging platform to monitor fault precursor on-state resistance," in 2015 IEEE IEMDC, Coeur d'Alene, Idaho, 2015, pp. 1-23.

[20] M. Pecht and Jie Gu. (2009, June). Physics-of-failure-based prognostics for electronic products. Trans. Inst. Meas. Control. 31(3-4). pp. 309-322

[21] R. Bayerer, T. Herrmann, T. Licht, J. Lutz, and M. Feller, "Model for Power Cycling lifetime of IGBT Modules," in CIPS, Nuremberg, Germany, 2008, pp. 1-6.

[22] C. Y. Yin, H. Lu, M. Musallam, C. Bailey, and C. M. Johnson, "A Physics-of-failure based Prognostic Method for Power Modules," in 2008 10th EPTC, Singapore, 2008, pp. 1190-1195.

[23] B. Saha, J. R. Celaya, P. F. Wysocki, and K. F. Goebel, "Towards prognostics for electronics components," in 2009 IEEE Aerospace Conference. Proc., 2009, Montana, USA, pp. 1-7.

[24] N. Patil, J. Celaya, D. Das, K. Goebel, and M. Pecht. (2009, June). Precursor Parameter Identification for Insulated Gate Bipolar Transistor (IGBT) Prognostics. IEEE Trans. on Reliability. 58(2), pp. 271-276.

[25] P. J. Lutz, "Packaging and Reliability of Power Modules," in 8th CIPS, Nuremberg, Germany, 2014, pp. 25-27.

[26] A. E. Ginart, I. N. Ali, J. R. Celaya, P. W. Kalgren, D. Poll, and M. J. Roemer, "Modeling SiO 2 Ion Impurities Aging in Insulated Gate Power Devices Under Temperature and Voltage Stress," in Annual Conf. of PHM, 2010, Portland. Oregon, pp. 1-10.

[27] M. Musallam, C. M. Johnson, C. Yin, C. Bailey, and M. MermetGuyennet, "Real-time life consumption power modules prognosis using on-line rainflow algorithm in metro applications," in 2010 IEEE ECCE, 2010, Atlanta, USA, pp. 970-977.

[28] S. Manzoor, N. M. Karim, and N. Soin. (2012, Nov). Analyzing pMOSFET Lifetime by Employing R-D Model \& MOS Device Theory. Applied Mechanics and Materials. 229-231, pp. 1626-1629.

[29] B. Ji, V. Pickert, W. Cao, and B. Zahawi. (2013, Dec). In situ diagnostics and prognostics of wire bonding faults in IGBT modules for electric vehicle drives. IEEE Trans. Power Electronics. 28(12), pp. 5568-5577.

[30] H. Lu, K. Ma, Z. Qin, P. C. Loh and F. Blaabjerg. (2016. June). Lifetime Estimation of MMC for Offshore. IEEE Journal of Emerging and Selected Topics in Power Electronics. 4(2), pp. 504-511.

[31] L. R. GopiReddy, L. M. Tolbert, B. Ozpineci, and J. O. P. Pinto. (2015, July-Aug). Rainflow Algorithm-Based Lifetime Estimation of Power Semiconductors in Utility Applications. IEEE Transactions on Industry Applications. 51(4), pp. 3368-3375.

[32] R. t. Have, B. Vermulst, and J. v. Duivenbode, "An approach to lifetime estimation of $\mathrm{SiC}$ MOSFETs subjected to thermal stress," in Proc. PCIM Eur., 2015, Nuremberg, Germany, pp. 1-9.

[33] D. Zhou, H. Wang, F. Blaabjerg, S. K. Kaer, and D. Blom-Hansen, "Real mission profile based lifetime estimation of fuel-cell power converter," 2016 IEEE 8th Int. Power Elec Motion Control Conf. IPEMC-ECCE Asia 2016, pp. 2798-2805, 2016.

[34] J. R. Celaya, A. Saxena, S. Saha, V. Vashchenko, and K. Goebel, "Prognostics of Power MOSFET." in 2011 IEEE 23rd ISPSD, 2011,
California, USA, pp. 160-163.

[35] Y. Zheng, L. Wu, X. Li, and C. Yin, "A relevance vector machine-based approach for remaining useful life prediction of power MOSFETs," in 2014 PHM, 2014, Hunan, China, pp. 642-646.

[36] K. Momoda, K. Endo, Y. Midoh, K. Miura, and K. Nakamae. "Prediction of performance degradation and lifetime for semiconductor devices using Markov chain model." in IEICE, 2014, Japan, pp. 1-5.

[37] J. R. Celaya, A. Saxena, C. S. Kulkarni, S. Saha, and K. Goebel, "Prognostics approach for power MOSFET under thermal-stress aging," in Proc. - Annual RAMS, 2011, Florida, USA, pp. 1-6.

[38] C. S. Kulkarni, J. R. Celaya, G. Biswas, and K. Goebel, "Prognostics of Power Electronics, methods and validation experiments," in 2012 IEEE AUTOTESTCON Proc., 2012, California, USA, PP. 194-199.

[39] A. Kleyner, A. Vasan, and M. Pecht, "A New Application for Failure Prognostics - Reduction of Automotive Electronics Reliability Test Duration." in Annual Conf. PHM, 2017, St. Petersburg, Florida, pp. 1-9.

[40] S. Dusmez and B. Akin, "Remaining useful lifetime estimation for degraded power MOSFETs under cyclic thermal stress," in 2015 IEEE ECCE, 2015, Montreal, Canada, pp. 3846-3851.

[41] S. Dusmez, H. Duran, and B. Akin. (2016, May). Remaining Useful Lifetime Estimation for Thermally Stressed Power MOSFETs Based on on-State Resistance Variation," IEEE Transactions on Industry Applications. 52(3), pp. 2554-2563.

[42] S. Dusmez and B. Akin, "Comprehensive parametric analyses of thermally aged power MOSFETs for failure precursor identification and lifetime estimation based on gate threshold voltage," in 2016 IEEE APEC, 2016, California, USA, pp. 2108-2113.

[43] S. Dusmez, M. Heydarzadeh, M. Nourani, and B. Akin. (2017, June). Remaining Useful Lifetime Estimation for Power MOSFETs Under Thermal Stress With RANSAC Outlier Removal. IEEE Transactions on Industry Informatics. 13(3), pp. 1271-1279.

[44] M. Heydarzadeh, S. Dusmez, M. Nourani, and B. Akin, "Bayesian remaining useful lifetime prediction of thermally aged power MOSFETs," in 2017 IEEE APEC, 2017, Florida, USA, pp. 2718-2722.

[45] T. Aggab, F. Kratz, P. Vrignat, and M. Avila, "Remaining Useful Life prediction method using an observer and statistical inference estimation methods." in Annual Conf. PHM, 2017, St. Petersburg, Florida, pp. 1-8.

[46] S. Saha, J. R. Celaya, V. Vashchenko, S. Mahiuddin, and K. F. Goebel, "Accelerated Aging with Electrical Overstress and Prognostics for Power MOSFETs." in IEEE 2011 EnergyTech, 2011, Ohio, USA, pp. 1-6.

[47] J. R. Celaya, A. Saxena, S. Saha, K. F. Goebel, and nasagov AbhinavSaxena, "Prognostics of Power MOSFETs under Thermal Stress Accelerated Aging using Data-Driven and Model-Based Methodologies." in Annual Conf. PHM, 2011, Montreal, Canada, pp. 1-10.

[48] K. Medjaher and N. Zerhouni. (2013, October). Hybrid prognostic method applied to mechatronic systems. Int. J. Adv. Manuf. Technol. 69(1-4). pp. 823-834.

[49] S. Uckun, K. Goebel, and P. J. F. Lucas, "Standardizing research methods for prognostics," in 2008 Int. Conf. Progn. Heal. Manag. PHM, 2008, Denver, USA, pp. 1-10.

[50] M. Pecht and S. Kumar, "Data Analysis Approach for System Reliability, Diagnostics and Prognostics," in Pan pacific Microelectron. Symp., 2008, Kauai, Hawaii, USA, pp. 22-24.

[51] M. Ahsan, S. Stoyanov, and C. Bailey, "Data driven prognostics for predicting remaining useful life of IGBT," in Proc. ISSE, 2016, Pilsen, Czech Republic, pp. 273-278.

[52] T. Salunkhe, N. I. Jamadar, and S. B. Kivade. (2014, Nov). Prediction of Remaining Useful Life of Mechanical Components-A Review. Inter. Jour. Engineering Science and Innovative Technology. 3(6), pp. 125-135.

[53] H. M. Elattar, H. K. Elminir, and A. M. Riad. (2016, June). Prognostics: a literature review. Complex Intell. Syst. 2(2). pp. 125-154.

[54] S. Cheng and M. Pecht, "A fusion prognostics method for remaining useful life prediction of electronic products," in 2009 IEEE Int. Conf. Autom. Sci. Eng. CASE, 2009, Bangalore, India, pp. 102-107. 


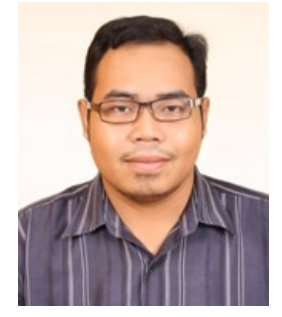

M. H. Abdul Halim received a Bachelor's Degree in Electrical and Electronic Engineering (Hons.) and M. Sc. in Electrical Engineering from the Universiti Teknologi MARA, Selangor, Malaysia, in 2011 and 2015, respectively. $\mathrm{He}$ is currently working toward a Ph.D. in Electrical engineering at the same university. From 2015 to 2017, he was a Lecturer in the Department of Electrical Engineering, SEGi University, Malaysia. In 2017, he join the International College of Technology Kanazawa, Japan as an Assistant Professor of Science and Technology. His primary research interest is prognostics, focused on the reliability prediction of power modules.

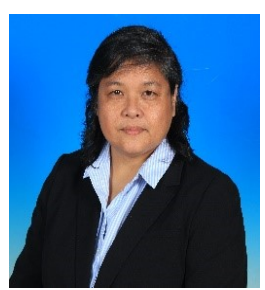

Professor Ir. Dr. Norlida Buniyamin graduated from the University of Adelaide, Australia with a Bachelor Degree in Electrical and Electronic Engineering (Hons.). She was a Research Fellow with the Malaysian Institute of Microelectronic Systems (MIMOS) before joining University Teknologi MARA as a lecturer in 1988. She then obtained an M.Sc. in Industrial Control System from the University of Salford, U.Kingdom in 1993 and a Ph.D. in the area of Knowledge Management for Manufacturing Enterprises in 2004 from the University of Manchester, Institute of Science and Technology (UMIST), U.K. She is now a Professor of Electrical Engineering at UiTM, a Fellow of the Institution of Engineers, Malaysia and Hon Fellow of the ASEAN Federation of Engineering Organisation (AFEO). Her current research interest is in Industrial Automation and Robotics, Biomedical Engineering, Knowledge Management and Engineering Education.

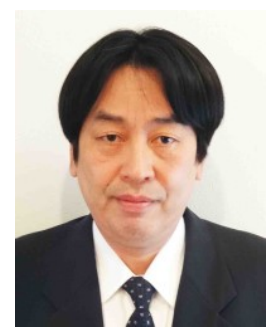

N. Naoe received the B.S, M.S, and Dr. Eng. in electrical engineering from Kanazawa Institute of Technology, Japan in 1987, 1989, 1992 respectively.

$\mathrm{He}$ is currently a professor at the International College of Technology, Kanazawa, Japan.

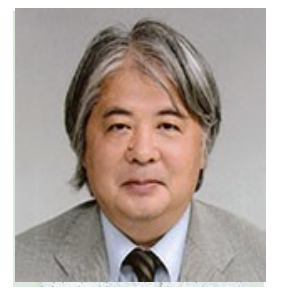

A. Imazawa received the $\mathrm{BSc}$ and $\mathrm{MSc}$ (Administration Engineering) from Keio University, Tokyo. Presently, he is a professor in the Department of Global Information and Management, International College of Technology, Kanazawa.

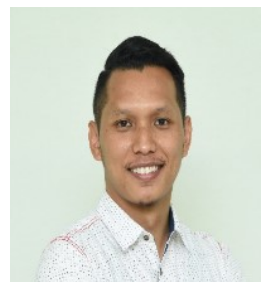

M. S. Rosman received a Bachelor Degree in Electrical and Electronic Engineering (Hons.) from Universiti Teknologi MARA (UiTM), Malaysia in 2011. With a background in the semiconductor industry, he persuing his Ph.D. in electrical engineering, focusing on semiconductor device and its correlation to thermal and failure analysis.

$\mathrm{He}$ has been directly involved in the semiconductor industry as a Test Engineer with Infineon Technologies (M) Sdn. Bhd. in Melaka since 2011. He has been actively engaged in the technical role throughout his carer and since 2018 has been participating in the technical ladder platform.

His latest publication in a few area such as cross-relations in electromagnetic and biology, semiconductor efficiency test in correlation with failure and knowledge of power transistors. 